\title{
Vomiting as an ictal manifestation of epileptic seizures and syndromes
}

\section{P PANAYIOTOPOULOS}

\author{
From the Division of Neurology and Clinical Neurophysiology, King Khalid University Hospital, Riyadh, Saudi \\ Arabia
}

SUMMARY Twenty-four out of 900 adult and children patients with epilepsy, were found to have vomiting during an ictus. All the 24 patients were children before puberty with a similar clinical pattern consisting of partial seizures which were mainly nocturnal. Ictal vomiting was always concurrent with other epileptic manifestations, more often deviation of the eyes and impairment of consciousness. The initial part of the ictus was short or prolonged for hours with frequent "marching" to hemi-convulsions and generalised seizures. Seventeen of the 24 children suffered from benign childhood epilepsies (BCE) with complete remission in long follow-up. A significantly higher association was found between ictal vomiting and the syndrome of BCE with occipital spikes ( $p<0.001)$ but not with centro-temporal spikes $(p<0.2)$. The recognition of this association may have important theoretical implications. On clinical grounds, it may prevent unnecessary investigations and undue concern.

Vomiting, a common manifestation of many organic and functional disorders, has received little attention in the epilepsies. It is, usually, totally neglected in the voluminous books on the epilepsies or mentioned briefly as a post-ictal event of generalised seizures. ${ }^{1}$ Ictal vomiting is thought to be so unusual that individual case reports have been published recently. ${ }^{2-4}$ Vomiting combined with seizures raises the suspicion of increased intracranial pressure for which a number of expensive and sometimes invasive investigations are initiated. In children, anxiety about epilepsy is coupled with uncertainty about the possible underlying pathology causing the vomiting. If no structural pathology is found, vomiting occurring in the course of an epileptic fit may be taken as evidence of coexisting migraine or as seizure activity consequent upon the migraine. ${ }^{5}$ The clinician has learned to relate vomiting to migraine but rarely if ever to epilepsy.

One of the more important advances in the epilepsies is the realisation that benign syndromes of partial/

Address for reprint requests: Prof C P Panayiotopoulos, 18 Kolonaki Square, Kolonaki, Athens, Greece.

Received 22 March 1988 and in revised form 6 June 1988. Accepted 13 June 1988 focal seizures exist in children. ${ }^{6}$ They are classified amongst the "age and localisation-related idiopathic epilepsies" (ALRIE), representing 10-20\% of epilepsies in children which completely remit by the middle teens. $^{6}$

In a recent prospective study of benign occipital lobe epilepsies, there were eight children with identical clinical and EEG findings in whom tonic deviation of the eyes and vomiting was reported consistently in the ictus. ${ }^{7}$ This observation prompted the present study.

\section{Methods}

The records of 900 patients with epilepsy were studied retrospectively for vomiting during the ictal phase of the seizures. Cases with vomiting occurring after a seizure or with a symptom-free interval between vomiting and a subsequent fit were not included. The patients were aged from 6 months to 80 years and were personal referrals, examined and followed, clinically and with electroencephalograms (EEG) by the writer in Athens in the last 15 years. The sources included physicians, paediatricians, other medical specialists and, to a lesser extent, relatives of the patients.

Four hundred and eighteen out of the 900 patients with onset of seizures before 13 years of age were pooled from this population and classified for the purpose of this study, in accordance with the criteria of the International League Against Epilepsy (ILAE). ${ }^{6}$ Ninety-four of these children 
fulfilled the clinical and EEG criteria for benign ALRIE (BALRIE). ${ }^{6}$

Fisher's exact probability test had been used for statistical evaluation.

\section{Results}

Twenty-four patients $(2 \cdot 7 \%$ of the total) were found to have unequivocal evidence of vomiting as an ictal manifestation during epileptic seizures. They all were children with partial seizures and are listed in table 1 amongst 418 patients with a similar onset of epilepsy. No ictal vomiting was reported in adults or in patients with generalised seizures. Furthermore, 17 of the 24 children with ictal vomiting suffered from benign ALRIE and are designated as group $A$. The remaining seven patients (group B) were suffering from idiopathic (four patients) or symptomatic (three patients) partial seizures. The association of ictal vomiting with BALRIE was significant ( $p>0.001)$.

\section{Clinical findings in ictal vomiting (table 2)}

The age of onset varied from 1 to 11 years but it was more frequent from 3-5 (mean 4.8) years. In only three children with BALRIE onset was after 5.5 years of age ( 7 years in 2 and 8.5 years in one).

Sex There were 14 boys and 10 girls. There was no apparent sex difference in BALRIE ( 9 girls and 8 boys).

Heredity Febrile convulsions were reported in one patient from each group. Family history of epilepsy was recorded in two patients with BALRIE. No history of migraine was obtained in the majority of families of the patients.

Table 1 Classification of seizures/syndromes with onset less than 13 years

\begin{tabular}{|c|c|c|c|}
\hline $\begin{array}{l}\text { Generalised Seizures/ } \\
\text { Syndromes }\end{array}$ & $\begin{array}{l}\text { Number of } \\
\text { Patients }\end{array}$ & $\%$ & $\begin{array}{l}\text { Ictal vomiting } \\
\text { Number of } \\
\text { Patients }\end{array}$ \\
\hline $\begin{array}{l}\text { Infantile-Neonatal } \\
\text { Seizures }\end{array}$ & 9 & $2 \cdot 2$ & 0 \\
\hline $\begin{array}{l}\text { Febrile Convulsions } \\
\text { Typical Absence Seizures } \\
\text { Atypical Absence } \\
\text { Seizures }\end{array}$ & $\begin{array}{l}23 \\
46 \\
25\end{array}$ & $\begin{array}{r}5.5 \\
11.0 \\
6.0\end{array}$ & $\begin{array}{l}\mathbf{0} \\
\mathbf{0} \\
\mathbf{0}\end{array}$ \\
\hline $\begin{array}{l}\text { Myoclonic Progressive } \\
\text { Epilepsies }\end{array}$ & 11 & $2 \cdot 6$ & 0 \\
\hline $\begin{array}{l}\text { Generalised Tonic Clonic } \\
\text { Seizures }\end{array}$ & 44 & $10 \cdot 5$ & 0 \\
\hline $\begin{array}{l}\text { Photosensitive Epilepsy } \\
\text { Juvenile Myoclonic } \\
\text { Epilepsy }\end{array}$ & $\begin{array}{r}13 \\
6\end{array}$ & $\begin{array}{l}3 \cdot 1 \\
1 \cdot 4\end{array}$ & $\begin{array}{l}0 \\
0\end{array}$ \\
\hline $\begin{array}{l}\text { Partial Seizures/Syndromes } \\
\text { Benign Childhood } \\
\text { Epilepsies }\end{array}$ & 94 & 22.5 & 17 \\
\hline $\begin{array}{l}\text { Complex Partial Seizures } \\
\text { Simple Partial Seizures } \\
\text { Total }\end{array}$ & $\begin{array}{r}70 \\
77 \\
418\end{array}$ & $\begin{array}{l}16 \cdot 7 \\
18 \cdot 4 \\
100\end{array}$ & $\begin{array}{r}2 \\
5 \\
24\end{array}$ \\
\hline
\end{tabular}

Ictal vomiting in BALRIE versus complex and simple partial seizures $p<0.001$. Complex versus simple partial seizures $p<0.2$.
Table 2 Profile of patients and seizures

\begin{tabular}{lll}
\hline & Group A & Group B \\
\hline Number of patients & 17 & 7 \\
Sex (Male/Female) & $8 / 9$ & $6 / 1$ \\
& Mean, SD, & Mean, SD, \\
& (range) & (range) \\
Age of onset (yr) & $4 \cdot 9,1 \cdot 6,(2-8 \cdot 5)$ & $4 \cdot 7,3 \cdot 5,(1-11)$ \\
Age of last seizure (yr) & $5 \cdot 6,1 \cdot 9,(2-10)$ & $5 \cdot 4,3 \cdot 1,(1-11)$ \\
Free of any seizures (yr) & $5 \cdot 3,3 \cdot 2,(1-11)$ & $1 \cdot 0,1 \cdot 7,(0-5)$ \\
Age in last follow up (yr) & $11 \cdot 2,4 \cdot 0,(5-20)$ & $7 \cdot 8,5 \cdot 8,(1-19)$ \\
& & \\
Ictal Marifestation of Seizures & \\
& Group A & Group B \\
& Number of & Number of \\
Vomiting & Patients & Patients \\
Lateral deviation of eyes & 17 & 7 \\
Impairment of & 12 & 3 \\
consciousness & 12 & 5 \\
Hemiconvulsions & 6 & 3 \\
Generalised convulsions & 8 & 3 \\
Aphemia & 2 & 2 \\
Oro-pharyngeal & 1 & 1 \\
movements & 2 & 0 \\
Salivation, coughing & 6 & 2 \\
Prolonged ictus with & & \\
vomiting & & \\
\hline
\end{tabular}

Ictal manifestations The ictal description was relatively similar for all. It was of a child who developed vomiting (all patients) and tonic deviation of the eyes (15 children). Consciousness may be preserved (seven patients). Aphemia (four children), oro-pharyngeal movements (two patients), coughing (one patient) and salivation (one patient) were less rare initial ictal events concurrent with vomiting. This stage may last for a few minutes (16 patients) or may be prolonged to hours (eight patients) before epileptic "marching" to hemiconvulsions and/or generalised convulsions (17 patients). One patient of group B proceeded to a convulsive status epilepticus.

Circadian distribution In all children with BALRIE seizures occurred during sleep. One child had two diurnal and one nocturnal seizures. In group B ictal vomiting was also nocturnal. It was diurnal in one patient and both nocturnal and diurnal in one other. Frequency of the seizures This was remarkably low. In BALRIE 15 children had only four seizures or less and in five, these were solitary. Only two patients had more than five seizures. In group B a similar situation was found.

Seizures not associated with vomiting Four out of the 17 patients with BALRIE experienced additional seizures without vomiting. There were two febrile convulsions (one child), a diurnal simple partial seizure (one), infrequent complex partial seizures (one) and two unclassified events involving loss of consciousness (one child). Patients of the group B were more prone to additional seizures without vomiting (five out of seven) with two patients experiencing simple partial seizures, one complex partial seizures 
and one neonatal convulsions and one other febrile convulsions.

Neurological examination was normal in all children with BALRIE. It was abnormal in the last three children in group B: two were retarded (one with congenital hydrocephalus) and one suffered from infantile hemiparesis.

Other associated features None of the children with BALRIE developed migraine or clinical photosensitivity during long-term follow up. None had any seizures with the visual hallucinations or post-ictal headache experienced by the majority of patients with childhood epilepsy with occipital paroxysms (CEOP) ${ }^{68}$ Computed tomography of the brain in 12 children were normal. They were abnormal in two patients of group B with symptomatic seizures.

Treatment and prognosis Follow-up of BALRIE patients was from 3 to 11 years from their last seizure in 14 of children. The mean seizure-free period for all children with BALRIE was $5 \cdot 3$ years, SD 3.2. All children were treated initially with one anticonvulsant drug, usually phenobarbitone and less frequently carbamazepine. In group B, follow-up was not adequate for the three patients with symptomatic epilepsy. Three patients with idiopathic epilepsy were free of seizures from 1 to 5 years.

Electroencephalographic findings Sixty seven out of the 94 children with BALRIE showed centro-temporal spikes only with no other spike locations. None of these children experienced ictal vomiting ( $p>0 \cdot 2$ ). Conversely, 13 patients showed occipital spikes only; nine of them had seizures with ictal vomiting (p $<0.001$ ). The remaining 14 children showed: posterior sagittal spikes (two children), unilateral frontal spikes (two), occipital with synchronous frontal (one) or centro-temporal spikes (four), centrotemporal spikes with somatosensory evoked spikes (SSES) (two patients) or with occipital spikes (three). Eight of them had ictal vomiting.

In the majority of the children with BALRIE, the EEG eventually became normal but spikes and other abnormalities persisted long after clinical remission.

In group B, three children had normal EEGs, in another three an excess of asymmetrical slow waves was found and in the remaining patient a generalised spike-slow wave discharge was recorded.

Case reports and EEG findings of eight patients have been reported elsewhere.

\section{Discussion}

Vomiting as an ictal manifestation in epileptic seizures has been documented with EEG and/or video-EEG recordings during the actual ictus. ${ }^{2-4}$ Vomiting in all 24 patients reported was concurrent with other welldocumented ictal events (focal convulsions, impair- ment of consciousness) and frequently preceded epileptic "marching" to hemiconvulsions and/or generalised seizures. Seizures during sleep were far more frequent than diurnal attacks in these patients. The difficulties in evaluating the sequence of ictal events in nocturnal seizures should be appreciated. However, vomiting was related unequivocally to the ictus in all the 24 patients; this was also confirmed by patients who did not lose consciousness and for seizures reliably witnessed from their onset. In addition, some seizures were very prolonged for 1 to 3 hours which was sufficient time for the parents to call for medical attention and sometimes medical specialists to observe.

Ictal vomiting in this study exceeds by far the incidence expected from the few published case reports. ${ }^{2-4}$ In spite of the retrospective nature of this study, the information about vomiting recorded from the patients and their parents-observers suggest that vomiting may be even more common as an ictal phenomenon. The physician is not used to inquire about vomiting in epileptic seizures. Furthermore, vomiting may be dismissed as irrelevant to the ictus or considered as a post-ictal event timed incorrectly by the observers.

The frequent association (18.1\%) of ictal vomiting and BALRIE merits further consideration. There are two BALRIE syndromes recently accepted by ILAE ${ }^{6}$ : (a) Benign childhood epilepsy with centro-temporal spikes (BCECTS). (b) Childhood epilepsy with occipital paroxysms (CEOP).

Children with epilepsy and SSES $^{8}$ may represent another form of BALRIE. In addition, a new syndrome of benign nocturnal childhood occipital epilepsy (BNCOE) has been described more recently.' This is a distinct syndrome of early, benign CEOP (BCEOP), with infrequent, mainly nocturnal seizures consisting of tonic deviation of the eyes and vomiting. Interictal EEGs show spike-slow waves in the occipital areas with an interesting, but non-specific, pattern of inhibition induced by central vision and fixation.?

It has been shown in this report that, although ictal vomiting is mainly associated with the early onset BCEOP $^{7}$ it may also occur in benign epilepsies of childhood with EEG spike foci located elsewhere. However, no association was found between ictal vomiting and spikes exclusively located in the centrotemporal region. These findings indicate differing clinical and EEG patterns amongst children with BALRIE.

The emetic process and its mechanisms have been recently reviewed.' Vomiting is controlled by the chemoreceptor trigger zone (CMRZ) and the vomiting centre (VC) which are two distinct medullary centres. In the epilepsies, ictal vomiting is difficult to explain in view of the unsuccessful attempts to induce it by 
cortical $^{10}$ and depth stimulation. ${ }^{11}$ It was elicited only by stimulation of the insula ${ }^{12}$ but this location cannot explain the frequent association of ictal vomiting with occipital epileptic discharges particularly. Jacome and FitzGerald $^{2}$ have implicated the right temporal lobe and the supplementary motor area in a patient with abundant multifocal interictal EEG abnormalities. It may be, however, unnecessary to seek for a cortical focus-centre for vomiting which is triggered by so many diverse chemical, physical and emotional stimuli.

Any hypothesis of ictal vomiting in epilepsies should explain the following clinical facts: (a) Vomiting is a manifestation of partial epilepsies, (b) It is agerelated and (c) It has a significantly higher association with one of the benign epileptic syndromes of childhood with occipital EEG paroxysms.

There are three possible explanations for these observations: (a) Vomiting is triggered by focal cortical epileptic discharges through cortico-VC or cortico-CMRZ VC connections. (b) It is the result of a vomiting-inducing substance released by the cortical electrical discharge, most likely acting through the chemoreceptor trigger zone. (c) Both epileptic cortical manifestations and vomiting are the result of a neurotransmitter mediated process which is excitatory both for the VC (or CMRZ) and the cortex.

The third possibility implicating an age-related neurotransmitter imbalance seems the most attractive. Certainly, it explains the otherwise confusing clinical manifestations of "migrainous" and "epileptic" events common to the benign childhood epilepsies with occipital paroxysms ${ }^{167}$; it requires no corticalvomiting focus and is in accordance with recent evidence on the role of neurotransmitter disturbances in epileptic conditions. ${ }^{13}$

In conclusion, ictal vomiting is a common clinical manifestation of the benign epilepsies of childhood, mainly those associated with severe EEG abnormalities in occipital regions. Recognition of this association is important for their management and prognosis, irrrespective of other theoretical implications and it may prevent unnecessary investigations and undue concern.

I thank Mr P Nastas for EEG recordings, Dr P
Hudgson for helpful comments, Dr A Lambourne for statistical and Mrs L Gallardo for secretarial assistance.

\section{References}

1 Panayiotopoulos CP. Difficulties in differentiating migraine and epilepsy based on clinical and EEG findings. In: Anderman F, Lugaresi E, eds. Migraine and Epilepsy. Boston: Butterworths, 1987:31-46.

2 Jacome DE, FitzGerald R. Ictus emeticus. Neurology 1982;32:209-12.

3 Mitchell WG, Greenwood RS, Messenbeimer JA. Abdominal epilepsy. Cyclic vomiting as the major symptom of simple partial seizures. Arch Neurol 1983;40:251-2.

4 Tinuper P, Aguglia U, Farnarier G, De Carvalho GV. Le vomissement: un symptome critique epileptique. Rev Electroencephalogr Neurophysiol Clin 1983;13:168-73.

5 Andermann F. Clinical features of migraine-epilepsy syndromes. In: Andermann F, Lugaresi E, eds. Migraine and Epilepsy. Boston: Butterworths, 1987: 3-30.

6 Commission on Classification and Terminology of the International League Against Epilepsy. Proposal for Classification of Epilepsies and Epileptic Syndromes. Epilepsia 1985;26:268-78.

7 Panayiotopoulos CP. Benign nocturnal childhood occipital epilepsy: A new syndrome with nocturnal seizures, tonic deviation of the eyes and vomiting. $J$ Child Neurol. (in press).

8 De Marco P, Tassinari CA. Extreme somatosensory evoked potentials (ESEP): An EEG sign forecasting the possible occurrence of seizures in children. Epilepsia 1981;22:569-75.

9 Davis CJ, Lake Bakaar GV, Grahame Smith DG, eds. Nausea and Vomiting: Mechanisms and Treatment. Berlin: Springer, 1986.

10 Penfield W, Jasper HH. Epilepsy and the Functional Anatomy of the Human Brain. Boston: Little, Brown and Company, 1954.

11 Van Buren JM. The abdominal aura: A study of abdominal sensations occurring in epilepsy and produced by depth stimulation. Electroencephalograph Clin Neurophysiol 1963;15:1-19.

12 Penfield W, Faulk ME. The insula: Further observations on its function. Brain 1955;78:445-70.

13 Morselli PL, Lloyd G, Löscher W, et al, eds. Neurotransmitters, Seizures and Epilepsy. New York: Raven Press, 1981. 